Article

\title{
Allogeneic Demineralized Dentin Matrix Graft for Guided Bone Regeneration in Dental Implants
}

\author{
In-Woong Um ${ }^{1}$, Jeong-Kui Ku ${ }^{2} *{ }^{\circledR}$, Yu-Mi Kim ${ }^{1}{ }^{(0)}$, Pil-Young Yun ${ }^{3}{ }^{(D}$, Na-Hee Chang ${ }^{4}$, \\ Young-Kyun $\mathrm{Kim}^{3}(\mathrm{D})$ and Yonghoon Choi ${ }^{5}$ (D) \\ 1 R\&D Institute, Korea Tooth Bank, Seoul 03011, Korea; h-bmp@hanmail.net (I.-W.U.); \\ yumi0825@hanmail.net (Y.-M.K.) \\ 2 Department of Oral and Maxillofacial Surgery, Section of Dentistry, Armed Forces Capital Hospital, \\ Armed Forces Medical Command, Seongnam 13574, Korea \\ 3 Department of Oral and Maxillofacial Surgery, Section of Dentistry, Seoul National University Bundang \\ Hospital, Seongnam 13620, Korea; pilyoung@snubh.org (P.-Y.Y.); kyk0505@snubh.org (Y.-K.K.) \\ 4 Biomedical Research Institute, Seoul National University Bundang Hospital, Seongnam 13620, Korea; \\ r0387@snubh.org \\ 5 Department of Conservative Dentistry, Section of Dentistry, Seoul National University Bundang Hospital, \\ Seongnam 13620, Korea; yhchoi@snubh.org \\ * Correspondence: kujk123@gmail.com; Tel.: +82-31-725-6184; Fax: +82-31-706-0987
}

Received: 10 June 2020; Accepted: 3 July 2020; Published: 7 July 2020

check for updates

\begin{abstract}
Autogenous and allogeneic demineralized dentin matrices (Auto-DDM and Allo-DDM, respectively) are currently used for guided bone regeneration (GBR). Buccal marginal bone (BMB) resorption is critical for successful implant integration. This study analyzed BMB resorption around dental implants for GBR between the control group (Auto-DDM graft) and experimental group (Allo-DDM graft). From 2014 to 2019, we enrolled 96 patients (59 males, 37 females, average 57.13 years) who received GBR (52 and 44 using Allo-DDM and Auto-DDM, respectively,) without a barrier membrane and a simultaneous single dental implantation (54 in the maxilla and 42 in the mandible). BMB height was measured immediately after GBR, at prosthetic loading, and 12 months after loading. BMB resorption was classified as initial resorption (between GBR and prosthetic loading) and functional resorption (during 12 months after prosthetic loading). The differences in the BMB levels of Auto-DDM and Allo-DDM were analyzed between the initial and functional resorption stages by independent sample $t$-test. Auto-DDM and Allo-DDM showed similar BMB changes in initial resorption $(0.73 \pm 0.97$ and $0.72 \pm 0.77 \mathrm{~mm}$, respectively) and functional resorption $(0.69 \pm 0.81$ and $0.48 \pm 0.58 \mathrm{~mm}$, respectively) without a significant difference between the maxilla and mandible. For GBR, Allo-DDM is comparable to Auto-DDM in terms of BMB resorption.
\end{abstract}

Keywords: allogeneic demineralized dentin matrix; buccal marginal bone; demineralized dentin matrix; dental implant; guided bone regeneration

\section{Introduction}

Autogenous demineralized dentin matrix (Auto-DDM) has been widely used in implant dentistry in Korea since 2008 for socket preservation, alveolar ridge augmentation, sinus augmentation, and guided bone regeneration (GBR) associated with dental implants [1,2]. GBR is dental surgical procedure that is predominantly applied to support new hard tissue growth on an alveolar ridge to allow stable placement of dental implants [3]. The rationale for the use of demineralized dentin matrix (DDM) on GBR is based on the structural and biochemical similarities between dentin and bone. DDM is defined as an acid-insoluble, highly cross-linked type I collagen (95\%) with collagenous and matrix-binding proteins such as transforming growth factors (TGFs), insulin growth factor (IGF), fibroblast growth 
factor (FGF), and bone morphogenetic protein (BMP) [4,5]. Although fabrication process of DDM removed dental stem cells [6,7], DDM is an "inductive substrate" due to transformation of the fibroblasts of the mesenchymes into cartilage or bone in the extra-skeletal site. Transforming factors in dentin induce the growth of undifferentiated mesenchymal cells, and these cells are converted into chondroblasts and osteoblasts to form new bones [8]. Consequently, Auto-DDM has shown promising clinical and histological results as an alternative to autogenous bone grafts without the limitations of donor availability, risk of infection at the donor site, and marked resorption rates of $\geq 50 \%$ [9].

Kim et al. [1] reported six cases of GBR using Auto-DDM (AutoBT, Korea Tooth Bank, Seoul, Korea) with simultaneous implant placement. At average 4.5-month after GBR, histologic evaluation of each case highlighted the excellence of AutoBT for bone regeneration with osteoconduction and osteoinduction. A report of a previous case of long-term follow-up (5 years) reported $1 \mathrm{~mm}$ of buccal marginal bone resorption around the implant with the formation of cortico-cancellous bone, approximately six years after socket preservation in 2016 [9]. So far, Auto-DDM accelerates bone regeneration in numerous human clinical studies [10,11]. Recently, a fragmented, partially demineralized tooth matrix was used for maxillary sinus augmentation. Histological analysis revealed neither inflammatory nor infective reactions against the tooth graft. Granules appeared surrounded by newly formed bone and partially resorbed, indicating ongoing remodeling [12]. Another clinical study using autogenous mineralized dentin matrix for socket preservation, to compare the alveolar contractions as well as to analyze the densitometric differences between both post-extraction sockets presented that the dimensional contraction of the post-extraction socket in the study group was lower than that in the control group at 16 weeks after surgery, both vertically and horizontally [13].

The Auto-DDM has some limitations. Primarily, it is time-consuming because of the inevitable surgical extraction and the external manufacturing process required to prepare the material. Following, the amount of Auto-DDM obtained is unpredictable as it depends on several clinical conditions, such as dental caries, restorations, and prostheses in the harvested teeth. Therefore, the application of allogeneic DDM (Allo-DDM) has been proposed to overcome the shortcomings of Auto-DDM.

In 1967, Bang and Urist [14] proved that allogeneic, demineralized, and lyophilized dentin induced new bone formation in an in vivo study. Subsequently, Allo-DDM exhibited excellent bone formation capacity without eliciting an immune response or antigenic effect in experimental studies of the early 1970s and 80s $[15,16]$. Further, clinical trials revealed that allogeneic freeze-dried dentin matrix demonstrated a high osteoinductive potential in periodontal osseous defects [17]. Allo-DDM in the cystic lesions of the jaw in 33 patients presented excellent bone healing without immunologic complications [18]. In 2014, successful clinical outcomes were reported with Allo-DDM procured from a biological family member for alveolar ridge and sinus augmentation [19]. Subsequently, Kim et al. reported that the use of Allo-DDM for alveolar bone augmentation in 18 patients did not elicit an immune response or antigenicity and showed clinical results similar to those of Auto-DDM [20]. In 2017, the first randomized, controlled, prospective, a clinical pilot study on comparative alveolar ridge preservation using allogenous tooth graft versus allogenous free-dried bone graft in 15 patients was reported in India [21]. This study showed that the mineralized whole tooth allograft (WTA) consistently indicated superior results, demonstrating the least reduction in the alveolar crest height. Histological analysis also confirmed the new bone formation at the WTA sites.

Even though several clinical studies have been published in the 2010s, there was only one randomized controlled clinical study for socket preservation before implant placement. Most of the other studies were case reports, which evaluated the alveolar bone repair capacity by qualitative measurement that is insufficient to confirm the clinical efficacy of Allo-DDM application. So far, few studies have quantitatively analyzed the clinical effects of Allo-DDM in relation to dental implants. Furthermore, evaluation of buccal marginal bone (BMB) resorption around dental implants before and after prosthetic loading has not yet been reported.

The purpose of this clinical pilot study was to analyze the BMB resorption between Allo-DDM and Auto-DDM in GBR around dental implants before and after prosthetic loading. We hypothesized 
that Allo-DDM grafted around dental implants would show similar BMB resorption to those of Auto-DDM within the success criterion, which is defined as BMB loss $<1.5 \mathrm{~mm}$ in the first year after prosthetic loading.

\section{Materials and Methods}

\subsection{Source of Allogeneic Demineralized Dentin Matrix (Allo-DDM) and the Fabrication of Demineralized Dentin Matrix (DDM)}

Allo-DDM was supplied by the Korea Tooth Bank (KTB, Seoul, Korea) that processed human tooth-derived bone graft materials under the Guidelines of Good Practice for Tooth Handling Institution from the Korea Ministry of Health and Welfare (KMHW) [22]. The impacted third molars and premolars extracted during orthodontic treatment were collected at designated dental clinics and sent to KTB to manufacture Allo-DDM. Generally, procurement, storage, processing, and packaging were performed separately for teeth obtained from each individual to conform to the "Guidelines" from KMHW, which states that no pooling of teeth from different patients should occur [22]. Briefly, the processing for Allo-DDM and Auto-DDM involved refrigeration of teeth in $70 \%$ ethyl alcohol followed by rinsing and removal of attached soft tissue and pulp using a retrograde technique. The dentin was crushed into particles $(300-800 \mu \mathrm{m})$, followed by defatting and demineralization using $0.6 \mathrm{~N} \mathrm{HCl}$ with a viral inactivation procedure (Patent: EP 2601982), as previously reported [23]. The DDM was finally sterilized, packaged, and sent to clinics to be stored at room temperature for allogeneic transplantation.

\subsection{Study Design}

This clinical pilot study was conducted between September 2014 and September 2019 at the Seoul National University Bundang Hospital (SNUBH) and approved by the Ethics Committee of SNUBH Institutional Review Board (IRB No. B-1910/570-109). The study was conducted following the principles of the Declaration of Helsinki for research on humans.

Ninety-six patients ( 59 men, 37 women; median age 57.13 years) who underwent a single tooth extraction and implant placement with GBR participated in this study. Auto-DDM or Allo-DDM was used for four-wall (minimum) defects with buccal vertical bone destruction in the maxilla and mandible under written informed consent (Table 1). Among other bone substitutes, the criteria for choosing Allo-DDM was completely dependent on the patient's decision. The average healing period, between GBR with implantation and prosthetic loading, was three (range, 3-4 months) and six (range, 6-8 months) in the mandible and maxilla, respectively. After the healing period, the implant was subjected to prosthetic loading. The time point to measure the BMB height after loading was 12 months (range, 12-18 months).

The inclusion criteria were as follows: (1) requirement for dental extraction and GBR for single implant placement; (2) age $\geq 20$ years; (3) the presence of dentition adjacent to the bone defect; (4) minimum four-wall alveolar bone defects with vertical loss of buccal bone, more than a third implant thread (2.5 mm) exposure, and (5) healthy status or well-controlled systemic disease(s) (6). Cone-beam computed tomography (CBCT) was performed immediately after GBR, after the healing period, and 12 months after the prosthetic loading. The exclusion criteria were as follows: (1) previous surgery with other bone grafts at the surgical site, (2) history or symptoms indicative of maxillary sinus disease, (3) current smoking habit, (4) poor plaque control and untreated chronic periodontitis, and (5) preexisting dental implants adjacent to the surgical site. 
Table 1. Demographic information of patients and buccal marginal bone (BMB) height at surgery (T1), at prosthetic loading (T2), and 12 months after loading (T3).

\begin{tabular}{|c|c|c|c|c|c|c|}
\hline & \multirow{2}{*}{$\begin{array}{c}\text { Age } \\
\text { (Years, SD) }\end{array}$} & \multirow{2}{*}{$p$-Value } & \multicolumn{4}{|c|}{ Buccal Bone Height (mm, SD) } \\
\hline & & & T1 & T2 & T3 & $p$-Value \\
\hline Total $(\mathrm{n}=96)$ & $57.13(8.11)$ & & $\begin{array}{l}10.78 \\
(1.84)\end{array}$ & $\begin{array}{l}10.15 \\
(1.82)\end{array}$ & $\begin{array}{c}9.80 \\
(1.64)\end{array}$ & $\begin{array}{c}<0.001 * \\
\text { (Between each stage) }\end{array}$ \\
\hline \multicolumn{7}{|l|}{ Sex } \\
\hline Male $(n=59)$ & $56.13(6.97)$ & $0.117+$ & $\begin{array}{l}11.31 \\
(1.69)\end{array}$ & $\begin{array}{l}10.66 \\
(1.81)\end{array}$ & $\begin{array}{l}10.22 \\
(1.68)\end{array}$ & $\begin{array}{l}\text { T1: } 0.397+ \\
\text { T2: } 0.788+\end{array}$ \\
\hline Female $(\mathrm{n}=37)$ & $58.73(9.00)$ & & $\begin{array}{l}11.09 \\
(1.81)\end{array}$ & $\begin{array}{l}10.45 \\
(1.86)\end{array}$ & $\begin{array}{c}9.91 \\
(1.80)\end{array}$ & T3: $0.576+$ \\
\hline \multicolumn{7}{|l|}{ Location } \\
\hline Maxilla $(\mathrm{n}=54)$ & $57.72(6.97)$ & $0.410+$ & $\begin{array}{l}11.46 \\
(1.69)\end{array}$ & $\begin{array}{l}10.68 \\
(1.99)\end{array}$ & $\begin{array}{l}10.14 \\
(1.87)\end{array}$ & $\begin{array}{l}\text { T1: } 0.136+ \\
\text { T2 } 0.531+\end{array}$ \\
\hline Mandible $(n=42)$ & $56.38(8.93)$ & & $\begin{array}{l}10.92 \\
(1.76)\end{array}$ & $\begin{array}{l}10.44 \\
(1.60)\end{array}$ & $\begin{array}{l}10.15 \\
(1.54)\end{array}$ & T3: $0.804+$ \\
\hline Types of DDM & & & & & & \\
\hline Auto-DDM $(\mathrm{n}=44)$ & $56.45(7.61)$ & $0.436+$ & $\begin{array}{l}11.76 \\
(1.84)\end{array}$ & $\begin{array}{l}11.09 \\
(1.70)\end{array}$ & $\begin{array}{l}10.45 \\
(1.77)\end{array}$ & $\begin{array}{l}\text { T1: } 0.004 \dagger \\
\text { T2: } 0.011 \dagger\end{array}$ \\
\hline Allo-DDM (n = 52) & $57.71(8.11)$ & & $\begin{array}{l}10.78 \\
(1.45)\end{array}$ & $\begin{array}{l}10.45 \\
(1.82)\end{array}$ & $\begin{array}{c}9.80 \\
(1.64)\end{array}$ & T3: $0.065+$ \\
\hline
\end{tabular}

BMB; buccal marginal bone. * Paired $t$-test. + Independent-sample $t$-test.

\subsection{Transplantation of DDM and Implant Placement}

Surgical procedures (extraction, implantation, and GBR) were performed by a single surgeon. Immediately after extraction, the implant (diameter: $3.8 \mathrm{~mm}$, length: 10, 11.5, and $13 \mathrm{~mm}$; Dio, Busan, Korea) was placed with simultaneous GBR using the DDM (Auto-DDM or Allo-DDM).

Under local anesthesia using 2\% lidocaine $\mathrm{HCl}$ with 1:100,000 epinephrine (Lidocaine $\mathrm{HCl}$; Huons, Seongnam, Korea), crestal and mesio-distal vertical incisions were made with a No. 15 blade (Braun Manufacturing, Frankfurt, Germany). Following mucoperiosteal flap elevation, tooth extraction was performed. For the atraumatic extraction, the surgeon did not perform osteotomy on the remaining bone around the tooth. Copious removal of granulation tissues was performed by molt curettage, and profuse saline irrigation was performed. The remaining buccal marginal bone was trimmed to at least $0.5 \mathrm{~mm}$ thickness or more by $2.0 \mathrm{~mm}$ round burr without damaging the mucoperiosteal flap. Dental implants were placed to achieve primary stability with sufficient alveolar bone width (Figure 1a). The DDM was applied to the GBR to repair the damaged buccal alveolar wall (Figure 1b). Primary closure of the surgical sites was achieved with simple interrupted sutures using 4-0 vicryl sutures (Ethicon, Somerville, NJ, USA) after releasing incisions and coronally repositioned flaps. Barrier membranes were not applied because the collagen portion of the DDM was sufficient to bind to the patient's blood (Figure 1c). Patients were instructed to rinse their mouth twice daily with a $0.1 \%$ chlorhexidine solution and take oral antibiotics $(625 \mathrm{mg}$, amoxicillin, Ilsung Pharmaceutical, Daejeon, Korea) twice daily for three days [24]. After three to six months, satisfactory clinical healing was observed in all patients without any sign of infection or graft failure, and the surgical site was re-opened for prosthetic loading. Implants were loaded with screw-retained provisional restorations. Further, a bone sample was harvested from the area overlying the implant cover screw using a surgical scalpel (Dentium, Seoul, Korea) from one patient who consented to undergo a biopsy (Figure 1d). The specimen was demineralized with $10 \%$ formic acid after fixation in 10\% neutral-buffered formalin. Paraffin sections (thickness $5 \mu \mathrm{m}$ ) were stained with hematoxylin and eosin (HE) for histological observation. 


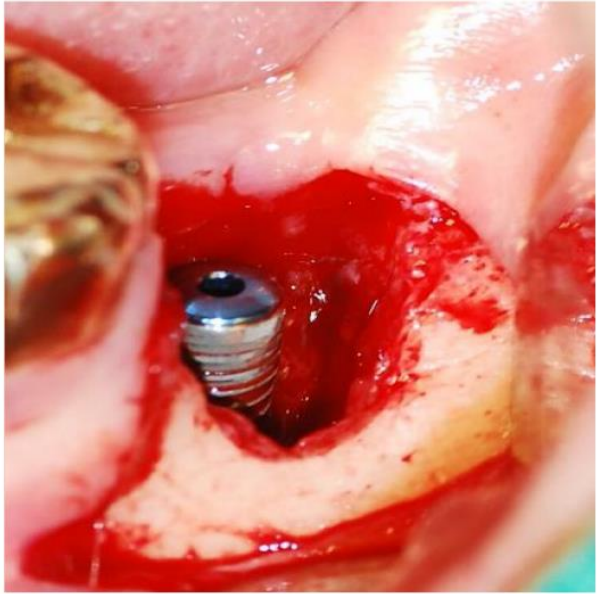

(a)

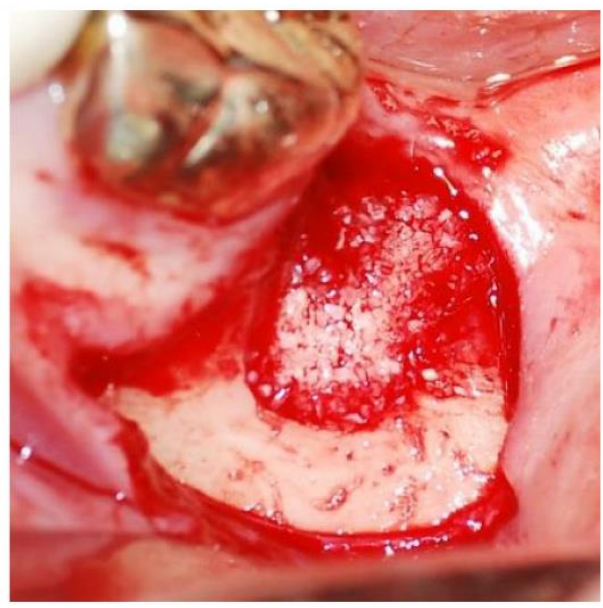

(c)

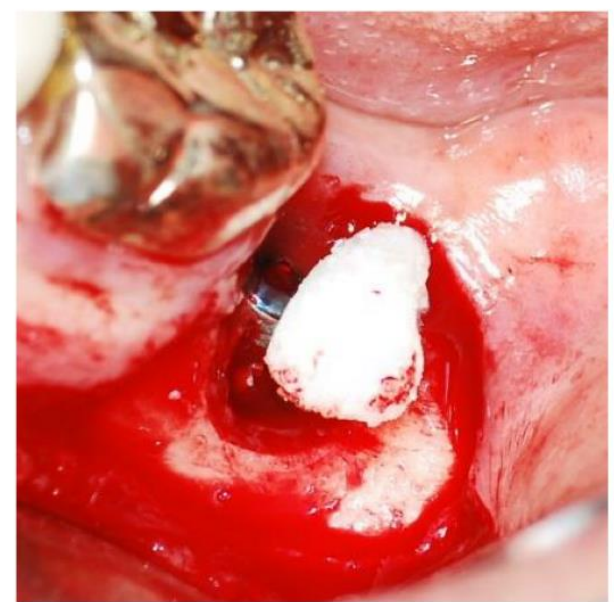

(b)

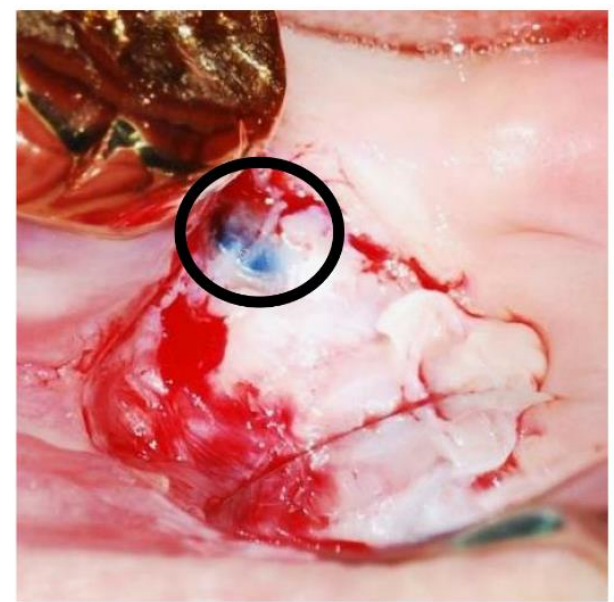

(d)

Figure 1. Surgical procedure. (a) Immediately after extraction, an implant was placed in the mandibular left second molar. (b) Allogeneic demineralized dentin matrix (Allo-DDM) was applied for guided bone regeneration. (c) Blood absorption and coagulation can be seen on Allo-DDM particles without covering the membrane. (d) At 4 months, surgical exposure to the prosthetic procedure showed hard tissue formation around the implant. Tissues over the cover screw of the implant (black circle) were harvested for histological examination. Allo-DDM: allogeneic demineralized dentin matrix.

\subsection{Measurement of Buccal Marginal Bone (BMB) Resorption Using Cone-Beam Computed Tomography (CBCT)}

BMB resorption around the implant was measured using linear cone-beam computed tomography (CBCT, Vatech, Seoul, Korea) measurement tools (EasyDent Viewer, Vatech, Seoul, Korea) on the center-aligned dental implant in a cross-sectional slice from the base of the implant to the crest of the buccal marginal bone height. The time points were immediately after implantation with GBR (T1: Figure 2a,d), prosthetic loading (T2: Figure 2b,e), and after 12 months of functional loading (T3: Figure 2c,f). On the cross-sectional view of the $\mathrm{CBCT}$, a vertical reference line was drawn from the radiolucent center of the cover screw to the mid-cylinder of the fixture. The horizontal reference line at the marginal crest of the bone, grafted, or formed, was drawn perpendicular to the vertical reference line (Figure 2a). The BMB was measured based on these reference lines relative to the marginal crest and dental implant apex at T1, T2, and T3. BMB resorption was classified as initial resorption (T1 to T2) and functional resorption (T2 to T3). If there was an increase in BMB height at 12 months compared with the baseline, the amount of resorption was set at zero. 
T1

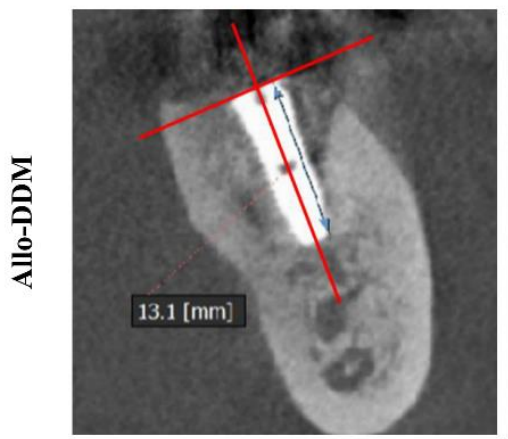

(a)

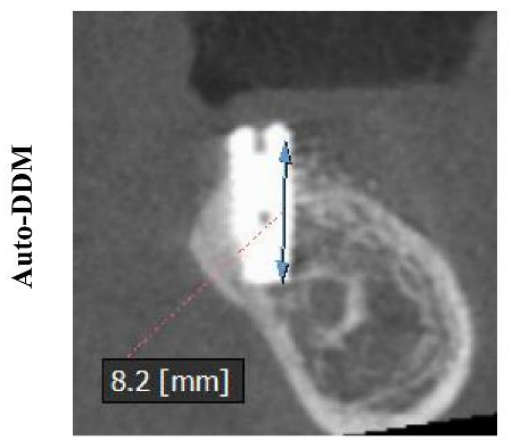

(d)
T2

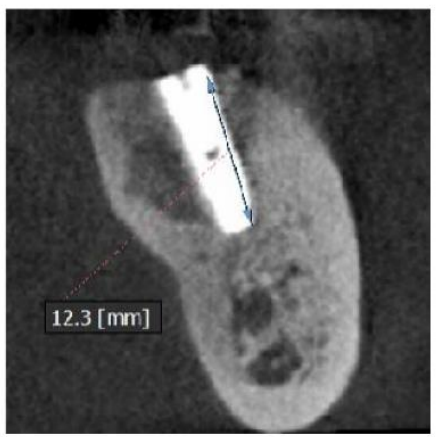

(b)

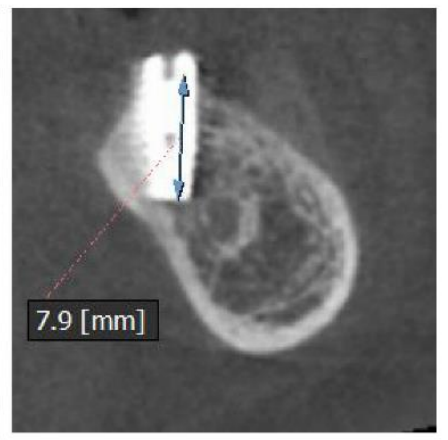

(e)
T3

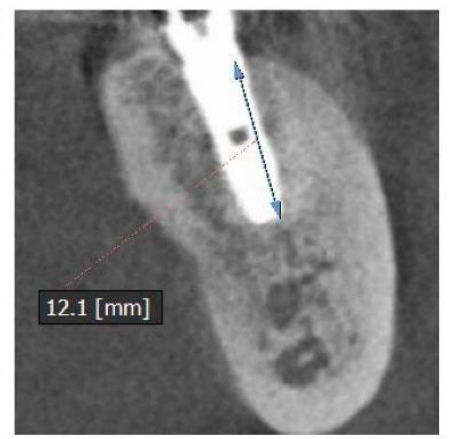

(c)

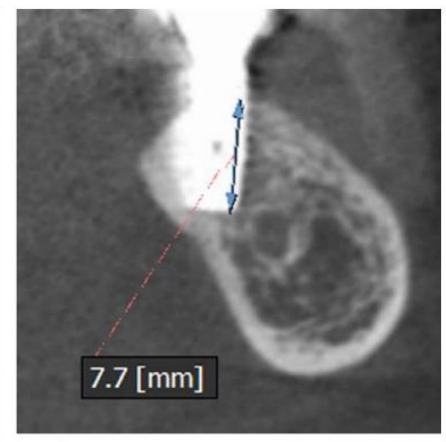

(f)

Figure 2. Buccal marginal bone (BMB) changes on cone-beam computed tomography (CBCT) images of allogeneic demineralized dentin matrix (Allo-DDM) $(\mathbf{a}, \mathbf{b}, \mathbf{c})$ and autogenous demineralized dentin matrix (Auto-DDM) (d,e,f) at T1 (immediately after implantation), T2 (before prosthetic loading), and T3 (12 months after prosthetic loading). (a,d) Cross-sectional views at implantation and simultaneous guided bone regeneration (GBR) with Allo-DDM and Auto-DDM. The vertical reference line passed through the middle of the implant from the apex to the center of the cover screw, and the horizontal reference line at the marginal crest of the grafted bone was drawn perpendicular to the vertical line. The BMB height was measured from the apex of the dental implant to the marginal crest of the grafted bone. (b,e) After 4 months of GBR, initial BMB resorption was measured based on the reference lines. This is the baseline for comparison with functional resorption at 12 months of prosthetic loading. (c,f) At 12 months after loading, the crestal bone around the implant neck showed gradual remodeling with cortical bone formation and developing cancellous bone support. Allo-DDM; allogeneic demineralized dentin matrix; Auto-DDM; autogenous demineralized dentin matrix; BMB, buccal marginal bone; GBR, guided bone regeneration; CBCT, cone-beam computed tomography.

\subsection{Statistical Analysis}

The parametric assumptions of the data were verified using the Kolmogorov-Smirnov test. Comparisons of mean age and BMB height change were analyzed using an independent sample $t$-test between the sexes and jaw types. The BMB height was analyzed using a paired $t$-test between every stage (T1-T2, T1-T3, and T2-T3). The BMB change between the initial and functional resorption was analyzed using a paired $t$-test for the difference between the stages. An independent sample $t$-test was used to analyze the differences in the initial and functional resorptions between the maxilla and mandible. Data are presented as mean \pm standard deviation, and statistical analysis was performed using SPSS 25.0 for Windows (SPSS Inc., Chicago, IL, USA).

\section{Results}

A total of 96 surgeries (54 in the maxilla and 42 in the mandible) were performed on 44 and 52 patients with Auto- and Allo-DDM, respectively. The total BMB heights were $10.78 \pm 1.84$, 
$10.15 \pm 1.82$, and $9.80 \pm 1.64 \mathrm{~mm}$ at $\mathrm{T} 1, \mathrm{~T} 2$, and T3, respectively. They presented a significant decrease between each stage $(P<0.001$, Table 1$)$. No significant changes observed in both the sexes and jaws for BMB height (Table 1). According to the types of DDM, the BMB heights were higher in Auto-DDM compared with the Allo-DDM (Table 1). At T1, the BMB heights of Auto-DDM and Allo-DDM were $11.76 \pm 1.84$ and $10.78 \pm 1.45 \mathrm{~mm}$, respectively $(P=0.004)$. At T2, the BMB heights of Auto-DDM and Allo-DDM were $11.09 \pm 1.70$ and $10.45 \pm 1.82 \mathrm{~mm}$, respectively $(P=0.011)$. At T3, the BMB heights of Auto-DDM and Allo-DDM were $10.45 \pm 1.77$ and $9.80 \pm 1.64 \mathrm{~mm}$, respectively $(P=0.065)$.

Total initial and functional resorptions were $0.72 \pm 0.86$ and $0.58 \pm 0.70 \mathrm{~mm}$, respectively, without significant differences between the periods. Both the initial resorption $(0.73 \pm 0.97$ and $0.72 \pm 0.77 \mathrm{~mm}$; $P=0.973)$ and functional resorption $(0.69 \pm 0.81$ and $0.48 \pm 0.58 \mathrm{~mm}, P=0.141)$ were not statistically different between the Auto- and Allo-DDM (Table 2, Figure 3).

Table 2. Initial and functional buccal marginal bone (BMB) resorption around implants using autogenous demineralized dentin matrix (Auto-DDM) and allogeneic demineralized dentin matrix (Allo-DDM).

\begin{tabular}{|c|c|c|c|}
\hline & $\begin{array}{c}\text { Initial Resorption } \\
\text { (T2-T1) }\end{array}$ & $\begin{array}{c}\text { Functional Resorption } \\
\text { (T3-T2) }\end{array}$ & $p$-Value \\
\hline Total & $0.72(0.86)$ & $0.58(0.70)$ & $\begin{array}{c}0.272 * \\
\text { (Initial vs. Functional resorption) }\end{array}$ \\
\hline Auto-DDM $(\mathrm{n}=44)$ & $0.73(0.97)$ & $0.69(0.81)$ & Initial resorption: $0.973+$ \\
\hline Allo-DDM $(\mathrm{n}=52)$ & $0.72(0.77)$ & $0.48(0.58)$ & Functional resorption: $0.141 \dagger$ \\
\hline Maxilla $(\mathrm{n}=54)$ & $0.84(0.98)$ & $0.64(0.76)$ & Initial resorption: $0.145+$ \\
\hline $\begin{array}{l}\text { Mandible }(\mathrm{n}=42) \\
\text { Maxilla }\end{array}$ & $0.58(0.66)$ & $0.51(0.61)$ & Functional resorption: $0.374+$ \\
\hline Auto-DDM $(\mathrm{n}=26)$ & $0.82(1.18)$ & $0.71(0.90)$ & Initial resorption: $0.899+$ \\
\hline $\begin{array}{l}\text { Allo-DDM }(\mathrm{n}=28) \\
\text { Mandible }\end{array}$ & $0.85(0.78)$ & $0.57(0.59)$ & Functional resorption: $0.502+$ \\
\hline Auto-DDM $(\mathrm{n}=18)$ & $0.59(0.54)$ & $0.67(0.67)$ & Initial resorption: $0.889+$ \\
\hline Allo-DDM $(\mathrm{n}=24)$ & $0.57(0.75)$ & $0.38(0.55)$ & Functional resorption: $0.133+$ \\
\hline
\end{tabular}

BMB; buccal marginal bone. * Paired $t$-test. + Independent-sample $t$-test.

Concerning the differences between the jaws, the initial resorption on the maxilla $(0.84 \pm 0.98 \mathrm{~mm})$ was higher than that on the mandible $(0.58 \pm 0.66 \mathrm{~mm})$ without significance $(P=0.145)$. However, the functional resorption was similar between the maxilla and mandible $(0.64 \pm 0.76$ and $0.51 \pm 0.61 \mathrm{~mm}$, $P=0.374)$ (Table 2, Figure 3).

In the maxilla, the resorption of Auto- and Allo-DDM were similar to the initial resorption $(0.82 \pm 1.18$; ranged between $0-2.00 \mathrm{~mm}$ and $0.85 \pm 0.78$; ranged between $0-1.80 \mathrm{~mm}, P=0.899)$ and functional resorption $(0.71 \pm 0.90$; ranged between $0-2.00 \mathrm{~mm}$ and $0.57 \pm 0.59 \mathrm{~mm}$; ranged between $0-1.90 \mathrm{~mm}, P=0.502)$. In the mandible, the resorption of Auto- and Allo-DDM was similar at the initial resorption $(0.59 \pm 0.54$; ranged between $0-3.70 \mathrm{~mm}$ and $0.57 \pm 0.75 \mathrm{~mm}$; ranged between $0-1.80 \mathrm{~mm}$, $P=0.899)$ and functional resorption $(0.67 \pm 0.67$; ranged between $0-3.20 \mathrm{~mm}$ and $0.38 \pm 0.55 \mathrm{~mm}$; ranged between $0-1.80 \mathrm{~mm}, P=0.133$ ) (Table 2, Figure 3). 


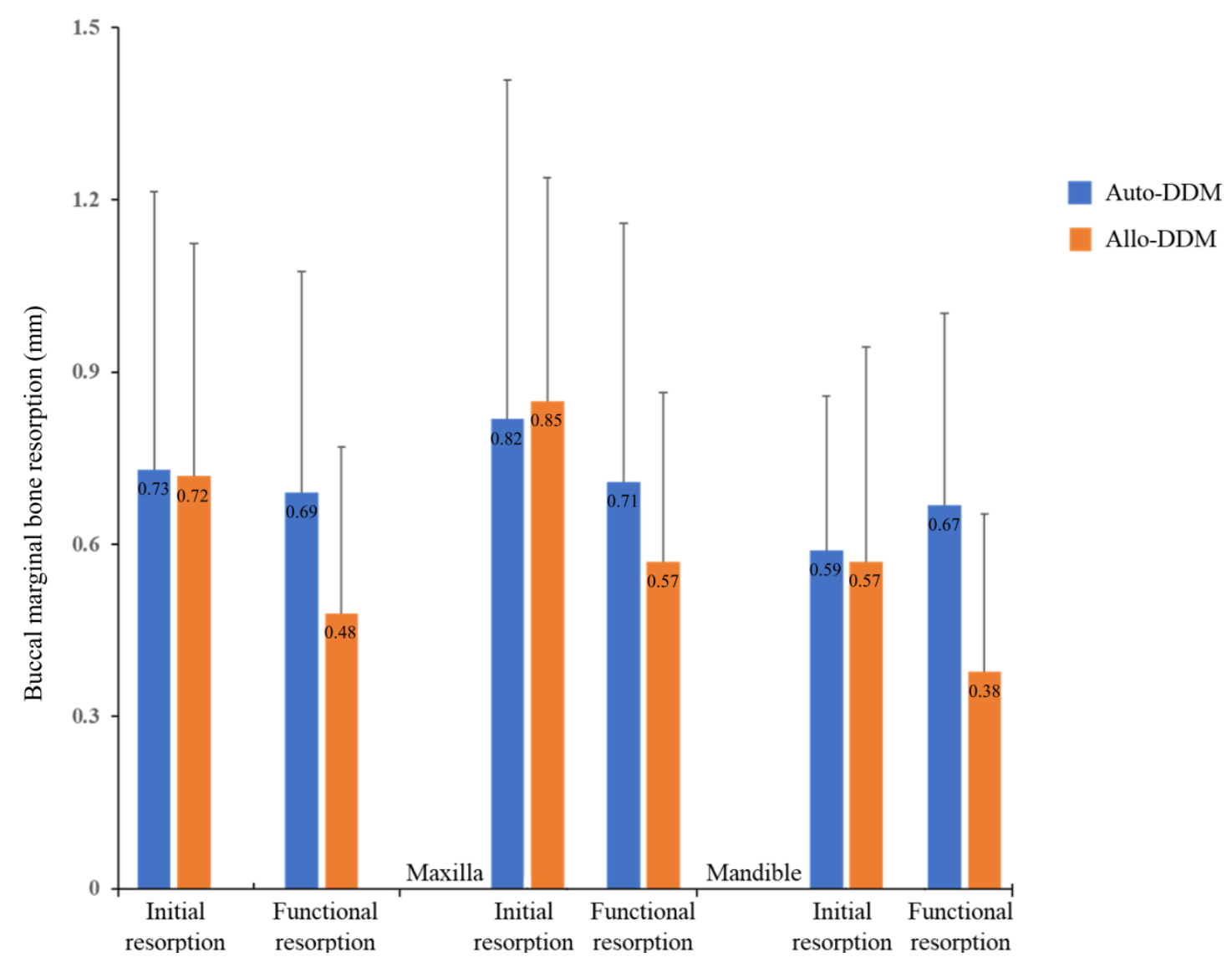

Figure 3. Buccal marginal bone (BMB) changes on cone-beam computed tomography images of autogenous demineralized dentin matrix (Auto-DDM) and allogeneic demineralized dentin matrix (Allo-DDM) according to the jaw (Table 2). The Auto-DDM and Allo-DDM grafts did not affect BMB resorption among the subgroups.

\section{Histological Observations}

Figure 4 shows HE-stained sections of Allo-DDM and Auto-DDM grafts at the time of prosthetic loading (T2). Woven bone formation, maturation with primary and secondary osteons, and remodeling with developing blood vessels (red arrowhead) are shown. Both the Allo-DDM and Auto-DDM particles (asterisk) were surrounded by newly formed osteoid with no gaps (black arrowhead). There was no inflammatory cell infiltration or impingement of the connective tissue into the DDM particles. 


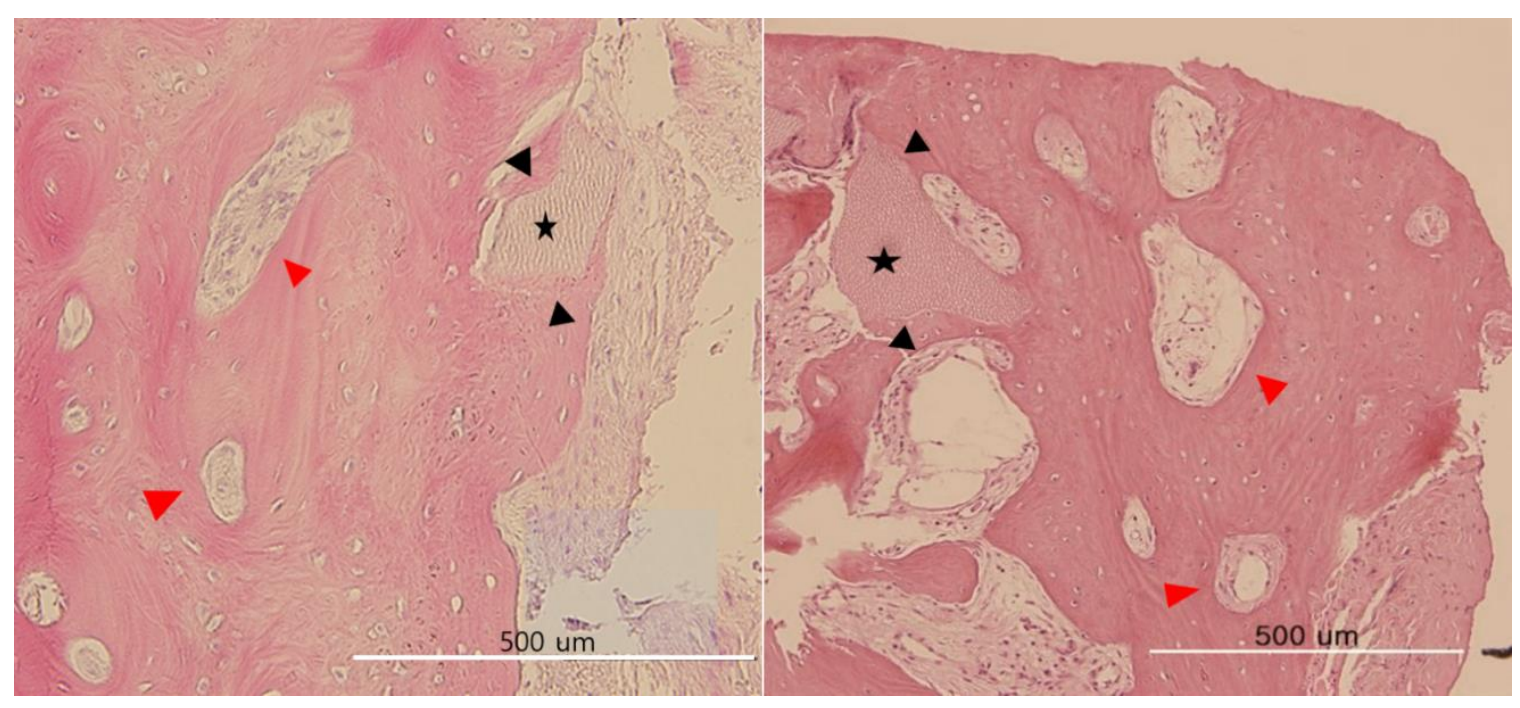

Figure 4. Histological findings of autogenous demineralized dentin matrix (Auto-DDM) and allogeneic demineralized dentin matrix (Allo-DDM) grafts at four months of guided bone regeneration. (Left; Allo-DDM, Right; Auto-DDM). Woven bone formation, maturation with primary and secondary osteons, and remodeling with developing blood vessels (red arrowhead). Newly formed osteoid surrounded the DDM particle (asterisk) closely without gaps (black arrowhead). There was no inflammatory cell infiltration or impingement of the connective tissue into DDM particles.

\section{Discussion}

The purpose of this clinical pilot study was to analyze BMB resorption during 12 months after prosthetic loading of a dental implant with GBR using Allo-DDM. To the best of our knowledge, there are no prior data on BMB resorption after prosthetic loading of dental implants with Allo-DDM as GBR material. We hypothesized that Allo-DDM grafted around the dental implant would not be inferior to Auto-DDM in terms of BMB resorption after 12 months of functional loading.

In this study, the initial resorption during the healing period before prosthetic loading was 0.73 and $0.72 \mathrm{~mm}$ with Auto- and Allo-DDM, respectively, which validates the previously reported clinical results (average $0.77 \mathrm{~mm}$ ) of Auto-DDM applications for GBR at three to six months [25]. Another study comparing Auto-DDM with Bio-Oss collagen demonstrated vertical bone loss ranging between 0.97 and $1.13 \mathrm{~mm}$, respectively, and showed that Auto-DDM was not inferior to Bio-Oss collagen [26]. A randomized, controlled, prospective, clinical pilot study using autogenous (mineralized)-tooth-graft in humans showed lower resorption values (average $0.28 \mathrm{~mm}$ ) in the alveolar crest height at four months compared with $\beta$-tricalcium phosphate $(\beta-\mathrm{TCP})$ (average $1.72 \mathrm{~mm}$ ) and ungrafted sites (average $2.60 \mathrm{~mm}$ reduction) [27]. Thus, the evidence states that BMB resorption of Allo-DDM in GBR during the healing period was very similar to the Auto-DDM application, although most of the Auto-DDM studies were based on socket preservation without implant placement. Concerning Allo-DDM applications, Joshi et al. [21] conducted a randomized, controlled, prospective, clinical study on allogeneic mineralized dentin grafts in 15 patients for GBR without implant placement. They reported $0.31 \mathrm{~mm}$ of initial $\mathrm{BMB}$ resorption four months after the graft and showed the least amount of initial BMB resorption after GBR in comparison to freeze-dried bone allograft (FDBA) (0.87-mm of resorption) [21]. These studies indicate that initial BMB resorption with Allo-DDM during the healing stage before prosthetic loading showed similar results to those of other studies using Auto-DDM, which is not inferior to Bio-Oss collagen, FDBA, or $\beta$-TCP [28-31].

Both functional BMB resorption of 0.69 and $0.48 \mathrm{~mm}$ in Auto-DDM and Allo-DDM, respectively, in this study complied with the long-term success criterion, which is defined as BMB loss $<1.5 \mathrm{~mm}$ within the first year after prosthetic loading [32]. With particulate autogenous bone grafts, the BMB loss around dental implants was $0.74 \mathrm{~mm}$ at three months, with up to $1.67 \mathrm{~mm}$ of resorption at 
12 months [33]. In a prospective clinical study of Auto-DDM versus Bio-Oss granules in GBR for immediate implantation in periodontal post-extraction sites, Auto-DDM $(1.9 \mathrm{~mm})$ and Bio-Oss $(2.0 \mathrm{~mm})$ showed similar results for BMB resorption values at six months postoperatively [11]. In a five-year follow-up of five patients who received Auto-DDM grafts for GBR, only one patient showed BMB resorption of $1 \mathrm{~mm}$ [9]. Even when the implant was placed without a bone graft, the BMB resorption was approximately $1 \mathrm{~mm}$ during the first year [34]. The authors noted that the bone-retaining group at the 1-year time point had thicker buccal bone walls at baseline compared with the bone-loss group. The initial buccal bone contour (thickness) was significantly associated with bone retention or loss at 1 year [34]. However, we did not measure the thickness of the remaining BMB before GBR because the resorbing buccal marginal bone was trimmed to at least $0.5 \mathrm{~mm}$ thickness or more.

Regarding the maxilla and mandible, maxillary BMB height showed more resorption than that of the mandible during both the initial and functional periods. However, Szava et al. reported that implants placed in the maxilla showed less bone loss than implants placed in the mandible after 1-year loading [35]. This result suggests that there are differences in remodeling procedures after GBR between the maxilla and mandible, and there may be greater volumetric shrinkage in the maxilla than in the mandible. The BMB resorption in CBCT was associated with a remodeling process rather than inflammatory destruction of the cortical bone around the implant neck [9]. Both in the maxilla and mandible, the BMB was less mineralized and mature before prosthetic loading. Twelve months after prosthetic loading, the BMB showed sound cortico-cancellous bone complexes surrounding the implant neck area without inflammatory destruction of the cortical bone. Therefore, the BMB resorption in this study was commensurate with the remodeling process rather than inflammatory bone resorption [36].

There have been previous concerns regarding the antigenicity of Allo-DDM in clinical applications. In the 1970s, several animal studies investigating the antigenicity of Allo-DDM showed a negligible inflammatory reaction. Therefore, the immune response to the first set of demineralized and lyophilized allogeneic dentin implants did not prevent bone induction $[15,16]$. In 1983, Schwartz examined the prevalence of allogeneic immune reactions elicited by implantation of allogeneic dentin using a blood test and reported no correlation between the incidence of immune reactions and the clinical or radiographic course of treatment. Moreover, there was a feeble correlation between the immune reaction and the HLA- or ABO-matched grades [37]. Carvalho et al. [38] and Gomes et al. [39] reported that the use of Allo-DDM was biocompatible with the process of bone repair and showed excellent rates of graft acceptance in rabbits treated with Allo-DDM. Kim et al., however, reported very similar results to those of Auto-DDM in qualitative and histological observations [20]. Although we obtained only one sample each Auto-DDM and Allo-DDM graft, histological findings presented excellent biocompatibility and satisfactory bone formation and remodeling, which corresponded to previous clinical reports of Auto- and Allo-DDM in 2016 [9,36]. In 2017, Joshi et al. [21] reported that the occasional immunizing effects of Allo-DDM did not contraindicate future clinical applications in humans.

The allogeneic applications of human DDM have several differences when compared with demineralized freeze-dried bone (DFDB), which has been extensively used in alveolar bone augmentation since 1980s [40] with a risk of transmission of viral diseases such as HIV, HBV, $\mathrm{HCV}$, and venereal diseases such as syphilis. Foremost, dentin is a cell-free matrix without blood vessels, while bone includes osteocytes and blood vessels, which are the principal carriers of viruses and antigenicity [41,42]. Additionally, DFDB is collected from the deceased, while DDM can be legally procured and collected from patients during dental treatment. Therefore, the risk of infection and transmissible viral diseases can be significantly reduced with the application of DDM [23,42]. Furthermore, demineralization has been confirmed as a viral inactivation method and is used by many tissue banks to validate viral clearance for DFDB $[43,44]$. Additionally, the demineralization of dentin can be a potent viral inactivation method for DDM [23]. Thus, the use of Allo-DDM has resolved the issues of antigenicity and reduced the risk of transmissible viral diseases $[23,43,44]$.

This clinical pilot study had several limitations. Foremost, the participants were unevenly distributed according to age, sex, site location (i.e., maxilla and mandible), or length of the implant. 
These factors affected the dimensional changes in BMB. Subsequently, this study was a clinical pilot study and not a randomized controlled trial. Consequently, more randomized controlled trials with appropriate control groups are necessary due to the heterogeneity of the data. Furthermore, the change in alveolar bone width during the healing period and thickness of BMB before GBR was not measured, which was a major contributing factor related to the fate of BMB resorption. Besides, histomorphometric analysis was not performed owing to a lack of consent.

\section{Conclusions}

Within the limitations of this study, we recommend that Allo-DDM in GBR show clinical results comparable to those of Auto-DDM in terms of BMB resorption during the first year of functional loading. This study can provide a rationale for further long-term randomized well-controlled trials to confirm the effectiveness of Allo-DDM.

Supplementary Materials: The following are available online at http://www.mdpi.com/2076-3417/10/13/4661/s1.

Author Contributions: This research was made possible by the personal contributions of the following persons: I.-W.U. for writing original draft preparation; J.-K.K., and Y.-K.K. for conceptualization and methodology; Y.-M.K. and P.-Y.Y. performed the data curation; N.-H.C. for software support; Y.C. performed the statistical analysis; I.-W.U. for financial support. All authors have read and agreed to the published version of the manuscript.

Funding: This research was supported by a grant of the Korea Health Technology R\&D project through the Korea Health Industry Development Institute (KHIDI), funded by the Ministry of Health and Welfare, Republic of Korea (Grant number: HI15C1535).

Conflicts of Interest: All the authors of this work wish to disclose that there are no financial or other conflicts of interest that might have biased the scientific information in this article.

\section{References}

1. Kim, Y.K.; Kim, S.G.; Byeon, J.H.; Lee, H.J.; Um, I.U.; Lim, S.C.; Kim, S.Y. Development of a novel bone grafting material using autogenous teeth. Oral Surg. Oral Med. Oral Pathol. Oral Radiol. Endod. 2010, 109, 496-503. [CrossRef]

2. Pang, K.M.; Um, I.W.; Kim, Y.K.; Woo, J.M.; Kim, S.M.; Lee, J.H. Autogenous demineralized dentin matrix from extracted tooth for the augmentation of alveolar bone defect: A prospective randomized clinical trial in comparison with anorganic bovine bone. Clin. Oral Implant Res. 2017, 28, 809-815. [CrossRef]

3. Ji-Young, L.; Young-Kyun, K.; Pil-Young, Y.; Ji-Su, O.; Su-Gwan, K. Guided bone regeneration using two types of non-resorbable barrier membranes. J. Korean Assoc. Oral Maxillofac. Surg. 2010, 36, 275-279.

4. Masaru, M.; Okubo, N.; Shakya, M.; Kabir, M.A.; Yokozeki, K.; Zhu, B.; Ishikawa, M.; Kitamura, R.; Akazawa, T. Dentin Materials as Biological Scaffolds for Tissue Engineering. In Biomaterial-Supported Tissue Reconstruction or Regeneration; IntechOpen: London, UK, 2019; pp. 1-12, ISBN 978-1-83880-378-0.

5. Murata, M.; Sato, D.; Hino, J.; Akazawa, T.; Tazaki, J.; Ito, K.; Arisue, M. Acid-insoluble human dentin as carrier material for recombinant human BMP-2. J. Biomed. Mater. Res. A 2012, 100, 571-577. [CrossRef] [PubMed]

6. Marrazzo, P.; Paduano, F.; Palmieri, F.; Marrelli, M.; Tatullo, M. Highly Efficient In Vitro Reparative Behaviour of Dental Pulp Stem Cells Cultured with Standardised Platelet Lysate Supplementation. Stem Cells Int. 2016, 2016, 7230987. [CrossRef] [PubMed]

7. Ballini, A.; Cantore, S.; Scacco, S.; Coletti, D.; Tatullo, M. Mesenchymal Stem Cells as Promoters, Enhancers, and Playmakers of the Translational Regenerative Medicine 2018. Stem Cells Int. 2018, 2018, 6927401. [CrossRef] [PubMed]

8. Urist, M.R.; Dowell, T.A.; Hay, P.H.; Startes, B.S. Inductive Substrates for Bone Formation. Clin. Orthop. Relat. Res. 1968, 59, 59-96. [CrossRef] [PubMed]

9. Kim, Y.K.; Lee, J.H.; Um, I.W.; Cho, W.J. Guided Bone Regeneration Using Demineralized Dentin Matrix: Long-Term Follow-Up. J. Oral. Maxillofac. Surg. 2016, 74, 515-e1. [CrossRef] [PubMed]

10. Minetti, E.; Giacometti, E.; Gambardella, U.; Contessi, M.; Ballini, A.; Marenzi, G.; Celko, M.; Mastrangelo, F. Alveolar Socket Preservation with Different Autologous Graft Materials: Preliminary Results of a Multicenter Pilot Study in Human. Materials 2020, 13, 1153. [CrossRef] 
11. Li, P.; Zhu, H.; Huang, D. Autogenous DDM versus Bio-Oss granules in GBR for immediate implantation in periodontal postextraction sites: A prospective clinical study. Clin. Implant Dent. Relat. Res. 2018, 20, 923-928. [CrossRef]

12. Minetti, E.; Palermo, A.; Contessi, M.; Gambardella, U.; Schmitz, J.; Giacometti, E.; Celko, M.; Trisi, P. Autologous tooth graft for maxillary sinus augmentation: A multicenter clinical study. Int. J. Growth Factors Stem Cells Dent. 2019, 2, 45-51. [CrossRef]

13. Del Canto-Díaz, A.; de Elío-Oliveros, J.; Del Canto-Díaz, M.; Alobera-Gracia, M.A.; Del Canto-Pingarrón, M.; Martínez-González, J.M. Use of autologous tooth-derived graft material in the post-extraction dental socket. Pilot study. Med. Oral Patol. Oral Cir. Bucal 2019, 24, e53-e60. [CrossRef] [PubMed]

14. Bang, G.; Urist, M.R. Bone induction in excavation chambers in matrix of decalcified dentin. Arch. Surg. 1967, 94, 781-789. [CrossRef]

15. Bang, G.; Nordenram, Å.; Anneroth, G. Allogenic demineralized dentin implants in jaw defects of Java monkeys. Int. J. Oral Surg. 1972, 1, 126-136. [CrossRef]

16. Bang, G. Induction of heterotopic bone formation by demineralized dentin in guinea pigs: Antigenicity of the dentin matrix. J. Oral Pathol. 1972, 1, 172-185. [CrossRef] [PubMed]

17. Fugazzotto, P.A.; De Paoli, S.; Benfenati, S.P. The use of allogenic freeze-dried dentin in the repair of periodontal osseous defects in humans. Quintessence Int. 1986, 17, 461-477.

18. Nordenram, A.; Bang, G.; Bernhoft, C.H. A clinical-radiographic study of allogenic demineralized dentin implants in cystic jaw cavities. Int. J. Oral Surg. 1975, 4, 61-64. [CrossRef]

19. Kim, Y.K.; Kim, S.G.; Lim, S.C. Familial tooth bone graft for ridge and sinus augmentation: A report of two cases. J. Korean Assoc. Oral Maxillofac. Surg. 2014, 40, 37-42. [CrossRef]

20. Kim, Y.K.; Bang, K.M.; Murata, M.; Mitsugi, M.; Um, I.W. Retrospective Clinical Study of Allogenic Demineralized Dentin Matrix for Alveolar Bone Repair. J. Hard Tissue Biol. 2017, 26, 95-102. [CrossRef]

21. Joshi, C.P.; D’Lima, C.B.; Samat, U.C.; Karde, P.A.; Patil, A.G.; Dani, N.H. Comparative Alveolar Ridge Preservation Using Allogenous Tooth Graft versus Free-dried Bone Allograft: A Randomized, Controlled, Prospective, Clinical Pilot Study. Contemp. Clin. Dent. 2017, 8, 211-217. [CrossRef]

22. Guidelines of Good Practice for Tooth Handling Institution. Korean Ministry of Health and Welfare. Available online: http:/www.mohw.go.kr/upload/viewer/skin/doc.html?fn=1526013681690_20180511134121. pdf\&rs=/upload/viewer/result/202006/ (accessed on 27 April 2018).

23. Um, I.; Choi, S.; Kim, Y.; Pang, K.; Lee, J.; Lee, M.; Kim, B. Measurement of hepatitis B virus DNA in fresh versus processed dentin from chronically infected patients. J. Transl. Med. 2018, 16, 351. [CrossRef] [PubMed]

24. Spellberg, B. The New Antibiotic Mantra-“Shorter Is Better”. JAMA Intern. Med. 2016, 176, $1254-1255$. [CrossRef] [PubMed]

25. Um, I.W.; Kim, Y.K.; Park, J.C.; Lee, J.H. Clinical application of autogenous demineralized dentin matrix loaded with recombinant human bone morphogenetic-2 for socket preservation: A case series. Clin. Implant. Dent. Relat. Res. 2019, 21, 4-10. [CrossRef] [PubMed]

26. Jung, G.-U.; Jeon, T.-H.; Kang, M.-H.; Um, I.-W.; Song, I.-S.; Ryu, J.-J.; Jun, S.-H. Volumetric, Radiographic, and Histologic Analyses of Demineralized Dentin Matrix Combined with Recombinant Human Bone Morphogenetic Protein-2 for Ridge Preservation: A Prospective Randomized Controlled Trial in Comparison with Xenograft. Appl. Sci. 2018, 8, 1288. [CrossRef]

27. Joshi, C.P.; Dani, N.H.; Khedkar, S.U. Alveolar ridge preservation using autogenous tooth graft versus beta-tricalcium phosphate alloplast: A randomized, controlled, prospective, clinical pilot study. J. Indian Soc. Periodontol. 2016, 20, 429-434. [CrossRef] [PubMed]

28. Iasella, J.M.; Greenwell, H.; Miller, R.L.; Hill, M.; Drisko, C.; Bohra, A.A.; Scheetz, J.P. Ridge preservation with freeze-dried bone allograft and a collagen membrane compared to extraction alone for implant site development: A clinical and histologic study in humans. J. Periodontol. 2003, 74, 990-999. [CrossRef]

29. Lekovic, V.; Kenney, E.B.; Weinlaender, M.; Han, T.; Klokkevold, P.; Nedic, M.; Orsini, M. A bone regenerative approach to alveolar ridge maintenance following tooth extraction. Report of 10 cases. J. Periodontol. 1997, 68, 563-570. [CrossRef]

30. Simon, B.I.; Von Hagen, S.; Deasy, M.J.; Faldu, M.; Resnansky, D. Changes in alveolar bone height and width following ridge augmentation using bone graft and membranes. J. Periodontol. 2000, 71, 1774-1791. [CrossRef] 
31. Lekovic, V.; Camargo, P.M.; Klokkevold, P.R.; Weinlaender, M.; Kenney, E.B.; Dimitrijevic, B.; Nedic, M. Preservation of alveolar bone in extraction sockets using bioabsorbable membranes. J. Periodontol. 1998, 69, 1044-1049. [CrossRef]

32. Papaspyridakos, P.; Chen, C.J.; Singh, M.; Weber, H.P.; Gallucci, G.O. Success criteria in implant dentistry: A systematic review. J. Dent. Res. 2012, 91, 242-248. [CrossRef] [PubMed]

33. Kim, T.Y.; Kim, Y.M.; Kim, J.Y.; Kim, M.R.; Kim, S.J. The retrospective study of marginal bone loss around dental implants according to different autogenous bone grafts. J. Korean Assoc. Oral Maxillofac. Surg. 2011, 37, 483-489. [CrossRef]

34. Takuma, T.; Oishi, K.; Manabe, T.; Yoneda, S.; Nagata, T. Buccal bone resorption around posterior implants after surgery: A 1-year prospective study. Int. J. Oral Maxillofac. Implant. 2014, 29, 634-641. [CrossRef] [PubMed]

35. Száva, D.-T.; Ormenișan, A.; Markovics, E.; Bögözi, B.; Mártha, K. Alveolar Bone Resorption Evaluation Around Single-piece Designed Bicortical Implants, Using Immediate Loading Protocol, Based on Orthopantomographs. J. Interdiscip. Med. 2017, 2, 328-331. [CrossRef]

36. Trindade, R.; Albrektsson, T.; Tengvall, P.; Wennerberg, A. Foreign Body Reaction to Biomaterials: On Mechanisms for Buildup and Breakdown of Osseointegration. Clin. Implant Dent. Relat. Res. 2016, 18, 192-203. [CrossRef]

37. Schwartz, O. Cell-mediated and humoral alloimmunreactions after subperiostal implantation of allogenic demineralized dentin in humans. Int. J. Oral Surg. 1983, 12, 95-105. [CrossRef]

38. Carvalho, V.A.; Tosello Dde, O.; Salgado, M.A.; Gomes, M.F. Histomorphometric analysis of homogenous demineralized dentin matrix as osteopromotive material in rabbit mandibles. Int. J. Oral Maxillofac. Implant 2004, 19, 679-686.

39. Gomes, M.F.; Banzi, E.C.; Destro, M.F.; Lavinicki, V.; Goulart, M. Homogenous demineralized dentin matrix for application in cranioplasty of rabbits with alloxan-induced diabetes: Histomorphometric analysis. Int. J. Oral Maxillofac. Implant 2007, 22, 939-947.

40. Glowacki, J.; Kaban, L.B.; Murray, J.E.; Folkman, J.; Mulliken, J.B. Application of the biological principle of induced osteogenesis for craniofacial defects. Lancet 1981, 317, 959-962. [CrossRef]

41. Tazaki, J.; Murata, M.; Yuasa, T.; Akazawa, T.; Ito, K.; Hino, J.; Nida, A.; Arisue, M.; Shibata, T. Autograft of human tooth and demineralized dentin matrices for bone augmentation. J. Ceram. Soc. Jpn. 2010, 118, 442-445. [CrossRef]

42. Smith, J.G.; Smith, A.J.; Shelton, R.M.; Cooper, P.R. Antibacterial activity of dentine and pulp extracellular matrix extracts. Int. Endod. J. 2012, 45, 749-755. [CrossRef]

43. Scarborough, N.L.; White, E.M.; Hughes, J.V.; Manrique, A.J.; Poser, J.W. Allograft safety: Viral inactivation with bone demineralization. Contemp. Orthop. 1995, 31, 257-261. [PubMed]

44. Swenson, C.L.; Arnoczky, S.P. Demineralization for inactivation of infectious retrovirus in systemically infected cortical bone: In vitro and in vivo experimental studies. J. Bone Joint. Surg. Am. 2003, 85, 323-332. [CrossRef] [PubMed]

(C) 2020 by the authors. Licensee MDPI, Basel, Switzerland. This article is an open access article distributed under the terms and conditions of the Creative Commons Attribution (CC BY) license (http://creativecommons.org/licenses/by/4.0/). 